\title{
Beliefs of Mothers, Nannies, Grandmothers and Daycare Providers Concerning Childcare ${ }^{1}$
}

\author{
Maria Lucia Seidl-de-Moura ${ }^{2}$ \\ Universidade do Estado do Rio de \\ Janeiro, Rio de Janeiro-RJ, Brazil \\ Deise Maria Leal Fernandes Mendes \\ Universidade do Estado do Rio de \\ Janeiro, Rio de Janeiro-RJ, Brazil
}

\author{
Luciana Fontes Pessôa \\ Pontificia Universidade Católica do Rio \\ de Janeiro, Rio de Janeiro-RJ, Brazil \\ Ana Carolina Monnerat Fioravanti-Bastos \\ Universidade Federal Fluminense, \\ Rio de Janeiro-RJ, Brazil
}

\author{
Dandara de Oliveira Ramos \\ Universidade do Estado do Rio de \\ Janeiro, Rio de Janeiro-RJ, Brazil \\ Luciana Brooking Teresa Dias \\ Universidade do Estado do Rio de \\ Janeiro, Rio de Janeiro-RJ, Brazil
}

\begin{abstract}
With the greater inclusion of women in the job market, the division of childcare has become increasingly more common. This paper's aim was to analyze potential differences among distinct profiles of caregivers regarding the valuation of Keller's parenting systems. A total of 120 caregivers (mothers, grandmothers, nannies and daycare educators) of children younger than one year of age participated in a semi-structured interview. Significant differences were found among the caregivers in regard to the importance they assigned to the different systems: face-to-face, body stimulation and basic care. Education also significantly influenced the valorization of face-to-face and basic care systems. The conclusion is that the caregivers presented a mixed parental style, both distal, enabling the experience of autonomy and separation, and proximal, valuing greater interpersonal relationships. This study sought to contribute to understanding the trajectories used to the development of self when different actors are involved in childcare.
\end{abstract}

Keywords: infants, cognitions, childcare behavior

\section{Crenças de Mães, Avós, Babás e Educadoras Sobre Cuidado de Bebês}

Resumo: Com a crescente inserção feminina no mercado de trabalho a divisão dos cuidados de crianças pequenas se torna uma prática cada vez mais comum. Este artigo analisou a valorização dos sistemas de cuidado parental de 120 mulheres em quatro subgrupos de cuidadoras de crianças com até um ano de idade: mães, avós, babás e educadoras de creche. Diferenças significativas foram encontradas entre as cuidadoras na ordenação destes sistemas. Mães, babás e educadoras de creche diferiram na valorização dos sistemas face a face, estimulação corporal e cuidados básicos. Foi encontrado efeito da escolaridade na valorização do sistema face a face e cuidados básicos. Conclui-se que as cuidadoras apresentaram estilo parental misto, tanto distal, propiciando uma experiência de autonomia e separação, quanto proximal, valorizando maior relação interpessoal. O presente trabalho buscou contribuir para a compreensão das trajetórias de construção do self quando diferentes atores estão envolvidos nas rotinas de cuidado das crianças.

Palavras-chave: bebês, cognições, comportamento de cuidado da criança

\section{Creencias de las Madres, Niñeras, Abuelos y Educadores de Guardería Acerca de lo Cuidado de Bebés}

\begin{abstract}
Resumen: Con la creciente inserción femenina en el mercado de trabajo la división de la atención de los niños pequeños es una práctica cada vez más común. En este artículo se analiza la valoración de los cuidados parentales en 120 mujeres (cuatro subgrupos de cuidadoras de niños menores de un año de edad: madres, abuelas, niñeras y educadores de guardería). Se encontraron diferencias en la ordenación de los sistemas de cuidado: las madres, niñeras y educadoras de guardería difieren en los sistemas de cara a cara, la estimulación del cuerpo, y la atención básica. Efecto de la educación se encuentra en el sistema cara a cara y en la atención básica. Con un enfoque sociocultural y evolucionista de la psicología del desarrollo, este estudio trata de contribuir a la comprensión de las trayectorias de la construcción de uno mismo cuando diferentes actores están involucrados en el cuidado de los niños.
\end{abstract}

Palabras clave: lactante, cogniciones, conducta de cuidado del niño

The increasing number of women entering the job market in urban centers of various countries in recent decades is a socially relevant phenomenon that has attracted the attention of researchers from diverse backgrounds (Hansen \& Hawkes, 2009). The search for alternative

\footnotetext{
1 Support: National Council for Scientific and Technological Development (CNPq - Protocol No. 303748/2010-9).

2 Correspondence address:

Maria Lucia Seidl-de-Moura. Rua Fritz Feigl, 465. CEP 22750-600. Rio de Janeiro-RJ, Brazil. E-mail: mlseidl@gmail.com
}

or complementary childcare services provided to small children increases considerably as a result of this increased market inclusion. Even though collective childcare has been present in different times in history and is part of human societies in diverse cultural contexts (Lordelo, Carvalho, $\&$ Koller, 2002), presently this search is peculiar due to the current characteristics of different sociocultural contexts. In the United States for instance, it is estimated that $60 \%$ of children younger than five years old (12 million children) spend part of the day under the care of people other than family members (Chen, 2013). 
In Brazil, $43 \%$ of the economically active population is composed of women aged between 25 and 49 years old. Among these, $55 \%$ have children up to two years old (Instituto Brasileiro de Geografia e Estatística [IBGE], 2010). These children are probably cared for by adults other than their mothers for at least part of the day.

This paper's aim was to analyze the beliefs of different caregivers in a specific context. For that, a sociocultural and evolutionary perspective that assumes an inseparable link between biological and cultural aspects was adopted. The orientation is interactionist, comprising human development as a process that is the result of evolution by natural selection as a species, but which takes place in a historical time and in a particular cultural context.

The context in which development takes place includes physical (instruments, housing conditions, food, etc.) and social aspects (actors, roles, organizations). The dynamics of alternative childcare can be understood as part of the process and conditions in which development takes place. In this dynamics, we highlight what Super and Harkness (2014) call the "psychology of caregivers", which includes beliefs, values, ideas, goals, and models. Hence, we need to identify this psychology in the context of alterative or complementary forms of childcare.

According to Keller (2013), human parenting is explained as a dynamic system composed of other different systems that integrate the experiences of interaction of the infant with all his/her different caregivers. This general system of parenting has the function of solving adaptive problems of human evolutionary history (Keller, 2013) and is explained according to shared cultural models. The specific care systems that compose the dynamics of human parenting include: primary care/basic care, body contact, body stimulation, object stimulation, face-to-face exchange, and narrative envelope.

The system of primary/basic childcare is described by Keller as an earlier phylogenetic system, focused on the provision of food, shelter, and hygiene. It can be assessed by the frequency and quality of food available, calories spent during breastfeeding, hygiene, how appropriate clothing is according to weather, etc. Its main psychological function is to ensure the infant's survival and growth, and reduce discomfort. Readiness in performing basic care activities ensures the child has a sense of safety and trust in the protection received from caregivers and is linked to a primary dimension of self-development. The system of body contact is manifested in the practice of carrying babies close to the caregiver's body (generally on the mother's back, front or hip). It ensures protection against danger, providing attachment and body regulation. It is considered a phylogenetically ancient system of attachment with the psychological function to promote an experience of safety. It favors the development of a sense of belonging, acceptance of trans-generational standards and values, and a harmonic and hierarchical family life.
Motor experiences promoted through touch and movement of the infant's body parts together with parental behavioral modulation and responses constitute the system of body stimulation (Keller, 2013). Its main psychological function is to encourage intensified body perception and effectiveness to act upon environmental resources.

In regard to the system of objects stimulation, Keller (2013) states its role is to enable the baby to acquire knowledge concerning the physical world, encouraging cognitive development and releasing the infant from dependency on social relationships. This childcare system is valued by Western, urban and industrialized societies and is related to metacognitive conceptions and exploratory activities.

In the face-to-face exchange system, eye contact is encouraged and is accompanied by the use of language in conversations with the baby. It stimulates perception of causal agency, uniqueness and self-efficacy. It is a system prevalent in contexts in which autonomy is valued, in urban Western societies with an individualist tendency.

Finally, the narrative envelope consists of the use of language on the part of caregivers. Conversations with the child aid the cultural appropriation of a conception of self and of other individuals. It consists of symbolic mediations in which the infant is involved through the speech of the child's main caregivers, especially the mother. This system is highly influenced by the mother's style of verbal communication with the infant, who is also part of the cultural model of the group to which she belongs.

Various studies conducted by Keller $(2012,2013)$ report two predominant parental styles: the distal and proximal. The parental strategy of the distal style is centered on face-to-face contact and interaction through objects, which enable the child to have an experience of autonomy and separation. The proximal style, in turn, is characterized by body contact and stimulation, ensuring the child experiences an interpersonal relationship of proximity and belonging to the cultural group (Martins et al., 2010).

Even though these are universal systems, how much each system is valued varies according to diverse cultural models and indicates different paths of socialization. Keller (2013) proposes two main paths: Western and non-Western (and mainly non-urban) paths that are related to two types of parental investment. In the first path, characteristic of non-Western traditional societies who live in non-urban environments, the mother performs routine tasks carrying the baby close to her body, virtually all the time, and shares the care with older siblings and other relatives. Therefore, there is greater body contact and cues that mother and child exchange and that are tactile and more proximal. In parallel, emotional care in this mode of parental investment supports a strong connection with the mother and is characterized by long periods of care that take place together with the adult's other tasks. At the same time, the mothers seem to expect a "calm child" who does not manifest emotions 
very intensively, especially those considered to be negative (Keller \& Otto, 2009).

In contrast, in the urban Western mode, the social environment is dyadic and attentional structure is exclusive. The child is breastfed and carried around for shorter periods of time, characterizing little body contact. Exclusive care as well as face-to-face interaction takes place in shorter periods of time, though this type of care predominates in the infant's first months of life. Interaction is mainly based on visual communication and vocal or verbal exchanges. In this mode of parental investment, care is also provided by people other than the parents, but they are usually paid caregivers (e.g. a nanny, daycare service). There is a tendency to promote independence early on and the expectation is that the child expresses emotionally with emotions strongly centered on her/himself, while smiles are encouraged very early (Keller \& Otto, 2009).

According to Keller (2013), based on different paths, the development of the self is guided in various directions: independent self, interdependent self or autonomous-related self, which derive from differentiated models of contact/care provided by parents to their children. Independence is privileged in the first model and comprises autonomy and separation, characterizing a distal relationship, emphasizing face-to-face exchanges and object stimulation. It is considered a pattern of interaction characteristic of Western educated, urban middle class families. The second model, interdependent, focuses on heteronomy and relationships, characterizing a proximal relationship. It emphasizes body contact and stimulation, considered to be characteristics of rural families with low socioeconomic and educational levels. The third autonomous-related model focuses on both autonomy and relationship and is an intermediary between the first and second models, characteristic of urban middle class families with higher levels of education in traditionally interdependent societies.

Some Brazilian studies have focused on these interests by investigating childcare systems and socialization paths in regard to the development of self in National contexts. Nonetheless, the awareness of differences in cultural and social contexts existing in Brazil imposes the need to investigate this diversity.

Concerned with comparing distinct contexts in the state of Santa Catarina, Brazil, Martins et al. (2009) analyzed parental care provided by mothers living in the capital and in cities in the interior of the state. The results concerning beliefs and care practices indicated that mothers in the interior of the state assign greater importance to basic care when compared to the mothers living in the capital. In regard to the face-to-face and object stimulation systems, however, in contrast with what the theoretical model proposed by Keller (2013) suggests, these systems were not more frequently used or more valued by the mothers from the capital than by the mothers living in the interior of the state. The authors explain such a result by noting sociodemographic characteristics (level of education and monthly income), concerning which there is not much distinction between the groups, which would imply to both groups traits of a culture described in the literature as being predominantly independent.

A larger study (Vieira et al., 2010) conducted with 600 Brazilian mothers, half living in the capitals and half living in smaller towns, investigated their beliefs in regard to practices and goals of socialization for their children and verified that, even though mothers of both contexts valued autonomy, those living in smaller towns considered the relational dimension to be the most important. Such results reinforce the need for studies to take into account the intra-cultural diversity and sociocultural variables that characterize a given context.

Based on a literature review of Brazilian studies conducted in 16 different contexts, Seidl-de-Moura, Carvalho and Vieira (2013) presented evidence of the autonomous-related model for the development of the self. They verified the relationship between the valorization of autonomy and relationship and the sociodemographic characteristics of these samples (varied levels of urbanization, diverse predominant cultural influences and educational levels). More recently, a Brazilian longitudinal study addressing the narrative envelope of mothers living in Rio de Janeiro reports similar evidence (Mendes \& Seidlde-Moura, 2013). The speech of mothers directed to their infants in the first six months of life indicates valorization of both autonomy and a proximal relationship.

The studies concerning parental studies have mainly addressed the mother as caregiver and we need to understand contemporaneous circumstances and the sociocultural context of care provided to small children. It seems opportune to undertake an investigation from the perspective of universal propensities of childcare, but with special attention to the diversity of paths that these care models assume due to cultural differences.

Even though the mother remains the main caregiver of children in their first year of life in urban environments, there are various alternatives that complement such care to varied degrees. Rapoport and Piccinini (2004) reviewed the literature and found non-maternal care modalities to include four main types: daycare centers and preschools; family daycare (small group of children in a caregiver's home); the child stays at home and is cared for by a nanny/babysitter; a relative takes care of the child either in the child's or the relative's home. The maternal grandmother is more frequently the relative providing care.

Each of these modalities involves caregivers with diverse experiences, educational levels, and also diverse systems of beliefs, which often result in different levels of valorization of practices. Hence, when we think about development in the diverse contexts and paths it can assume, we have to consider the impact of the beliefs held by different caregivers and how different practices can be performed in the context of care provided to children. 
One of the most common concerns in regard to different types of childcare is the consequences for the child's development and considering what would be better: leave the child in a daycare, with the grandmother, or hire a nanny. Studies have explored associations between alternative care in early childhood and various consequences in child development but there is no consensus in regard to the direction of such results. There are studies addressing negative impacts, such as difficulties in emotional development and self-regulation (Brooks-Gunn, Han, \& Waldfogel, 2002; Tanskanen, 2013) and including beneficial effects, such as enriching environments and broader initial cognitive abilities (Pluess \& Belsky, 2009). The inconsistency of results may be associated with the possibility of not considering these children's differential susceptibility in interactions and experiences.

Less frequent, but equally important, are concerns in regard to the type of context in which development takes place in the different modalities of childcare. In general terms, the cultural context of home, daycare, and grandmother's home is the same. The systems of beliefs and values and practices used, however, may vary among individuals of the same culture, be it due to a trans-generational factors, educational levels, or personal histories. There are few studies addressing beliefs of different caregivers. Greenfield, Flores, Davis and Salimkhan (2008) found differences in four pairs composed of American mothers (employers) and immigrant Latin American and American nannies in regard to their beliefs concerning practices and goals of development. These differences may be explained by the influence of sociodemographic variables in these cultural orientations, regardless of ethnic origin.

Brazilian research addressing different caregivers remains incipient. Bahia (2008) compared the beliefs of mothers and the providers in a daycare center in regard to the development of children and the relationship between daycares and families. Thirty-two adults (16 mothers and 16 providers) from a public daycare center in the city of Belém participated. The results indicated that the participants of both groups shared the same belief in regard to development (environmentalist), but had different conceptions as to the direction in which the family and/or daycare context influences child development. The authors emphasize that the daycare-family relationship should be considered bidirectional with content that goes beyond solving immediate problems. These concepts are closely linked to beliefs regarding working with and for children. The study, however, did not investigate the socialization goals or paths of development that were valued.

Friedlmeier, Schäfermeier, Vasconcellos and Trommsdorff (2008) compared German and Brazilian mothers and providers in both German and Brazilian daycare centers. German daycare providers valued independence more than Brazilian providers and the reverse was observed in regard to interdependence. Mothers and educators in the same cultural group did not differ in their orientation, though Brazilian providers had a greater tendency to value interdependence.

Ruela (2006) compared the socialization goals of mothers with at least one child up to seven years old and grandmothers in a rural community in Rio de Janeiro. The results indicated a predominance of a socio-centered orientation in the two groups and a greater valorization of practices guided by this orientation with more individualist characteristics. The self-improvement category was frequently mentioned by both. Additionally, the sharing of beliefs is greater in the intra-family environment. Subtle differences were observed that highlighted transformations between generations.

Mediation strategies of nannies with children during meal times (lunch) and in situations of free play in a domestic environment were identified and described by Fanti (2006). The author investigated relationships between mediations and some aspects regarding the nannies' work environment, their personal and cultural backgrounds. Fourteen nannies working in domestic environments participated in the study and were selected according to the age of the children under their care (from one-and-a-half years to three years old) and time working with the child (at least three months). The results indicated four patterns of mediation: authoritarian, directive, participative-directive, and participative. The nannies' beliefs were not assessed.

Even though some studies provide evidence of beliefs of diverse caregivers, knowledge concerning the psychology of different caregivers of small children in diverse contexts, especially in Brazil, is incipient. Gaps existing in the literature guided this study that focuses on the beliefs of caregivers in regard to exchange practices performed with infants. These beliefs are revealed according to the importance they attribute to the different systems of parental care. This study's general objective was to investigate the valorization of care systems in a group of different caregivers of children up to one year old (mothers, grandmothers, nannies, and daycare providers) in the city of Rio de Janeiro, Brazil. Based on an integrated view of value attributed to each of these systems, we sought to infer the path of the development of self that is given priority (independent self, interdependent self, or autonomous-related self).

Evidence of Brazilian studies (Seidl-de-Moura et al., 2013) conducted with mothers led us to hypothesize that the development of an autonomous-related self was given priority among the group of mothers addressed in this study. Based on the results of the trans-generational study by Ruela (2006), the hypothesis for the grandmothers was that greater value would be attributed to interdependent selves, while no hypothesis was formulated for the nannies and daycare providers due to a lack of studies enabling the formulation of hypotheses. 


\section{Method}

\section{Participants}

A total of 120 women were divided into four subgroups of caregivers: mothers, grandmothers, nannies, and daycare providers. These women were matched according to the complementary care chosen by the mother: grandmother, nanny, or daycare provider. Therefore, there were 60 mothers and 20 caregivers in each of the three subgroups. The children cared for by their grandmothers spent 12 hours per day with them $(S D=5.96)$ and 14 hours with their mothers $(S D=8.89)$ on average. The infants cared for by nannies spent 11 hours per day with them $(S D=6.65)$ and 12 hours with their mothers $(S D=7.16)$ on average. Schedules may overlap because mothers stay, at least part of the day, together with grandmothers and nannies. The children cared for by daycare providers spent seven hours per day with the providers $(S D=3.13)$ and nine hours with their mothers on average $(S D=5)$. This distribution of time is due to the fact that mothers leave their children in the daycare and mothers and daycare providers do not spend any time together.

The mothers had children of both genders up to one year old: $30.8 \%$ were two to five months old, $31.7 \%$ was six to nine months old, and $37.5 \%$ were from 10 to 12 months old. A total of $43.3 \%$ were boys and $56.7 \%$ were girls. In regard to the sample's level of education, in terms of the highest level reached, the distribution of participants per subgroup was: mothers with a bachelor's degree or graduate studies (84.9\%); completed high school (10\%), and completed middle school (5\%). The distribution among the grandmothers was: bachelor's degree or graduate studies $(50 \%)$, completed middle school $(30 \%)$ and finally, completed high school (20\%). The following distribution was observed in the group of nannies: completed middle school (70\%), completed high school (25\%), and bachelor's degree or graduate studies $(5 \%)$. Finally, most of the providers had completed high school (50\%), another considerable number of providers had a bachelor's degree (45\%), and a few had completed up to middle school (5\%).

As expected, there are differences in the level of education among the three groups. The mothers presented higher levels of education, followed by the grandmothers.

\section{Instruments}

Sociodemographic inventory. Instrument addressed age, education, time spent with the child, and the child's age and sex.

Semi-structured interview. Five pictures portraying the five Parental Care Systems discussed by Keller (2013) were presented to the participants. The sixth system, the narrative envelope, was not included in the interview because it does not allow a visual representation.

The pictures were specifically taken for this study and the portrayed mother consented to their use for research and publication. The pictures were prepared and submitted to judges to verify whether they consistently portrayed the systems and full agreement was achieved. The pictures presented a mother with her baby in the natural environment of her home. Each picture illustrated scenes representing one of the five systems: basic care (mother bathing the child), body contact (mother holding the baby close to her body), body stimulation (mother massaging the child's feet while the child was lying on the bed), object stimulation (baby lying on the bed while the mother shows a toy), and face-to-face interaction (infant on the mothers' arms, facing the mother).

\section{Procedure}

Data collection. Sixty pairs indicated by the research group were contacted (personally, via email or telephone) and invited to participate in the study after the Institutional Review Board approved the project. The participants signed free and informed consent forms. All the participants were individually interviewed. Mothers, grandmothers and nannies were interviewed in the mothers' home and daycare providers were interviewed in the daycare facility.

Each of the caregivers were asked to assess the pictures presented and order them according to the importance they assigned to each the situation for the baby's development. After ordination, they were asked to comment on each picture and on the importance they assigned to it. The interviews lasted 30 minutes on average.

Data analysis. Data concerning education were coded into three levels. The first included participants with incomplete, complete middle school, and part of high school; the second comprised participants who had completed high school and had incomplete college. The third level included those who had at least a bachelor's degree.

The interview regarding parental care systems was analyzed and the importance attributed to each system was identified according to the participant's choice of pictures. Scores attributed to each system followed the order of importance assigned by each participant to the pictures representing the five parental systems. Hence, the first picture chosen corresponded to the most important system and was scored the highest (five points). The second picture in order of importance received a score of four and so on, i.e. the fifth picture was scored a one. Each picture was scored according to its ordination; hence data are ordinal, leading to the use of non-parametric tests to analyze data (Field, 2009).

Three Chi-square tests were performed in order to verify differences regarding the ordination of childcare systems according to levels of education (below high school and middle school and above) of each subgroup of caregivers (grandmothers, nannies, and daycare providers). SPSS version 20.0 was used.

\section{Ethical Considerations}

This study was conducted using data from the project Autonomy and Interdependence in Families from Rio de Janeiro, submitted to and approved by the Institutional 
Review Board of the Universidade do Estado do Rio de Janeiro (Protocol No. 010.3.2010).

\section{Results and Discussion}

Data analysis indicated that the two types of childcare systems more frequently valued by the caregivers in general was body contact and face-to-face exchanges, as shown in Figure 1. The valorization of face-to-face exchanges is, according to Keller (2013), characteristic of urban contexts and socialization paths focused on the development of autonomy. On the other hand, this author states that body contact is more frequently valued in contexts that orient development toward interdependence and relationships. Therefore, the first hypothesis of this study is confirmed: i.e., there is an indication, in the studied urban context, of the mothers' tendency to value both autonomy and proximal relationships in the development of their children. In addition to the mothers, this finding is also extended to the other caregivers, for whom there was no evidence. These results follow the same direction of evidence found by Seidl-de-Moura et al. (2013), that there is a tendency toward a path of autonomous-related development.
In addition to this general tendency to value this type of path, we also sought to verify potential differences in the valorization of the five parental systems among the different groups of caregivers (mothers, grandmothers, nannies, and daycare providers). For that, we used the Kruskal-Wallis test; post hoc analyses for $2 \times 2$ comparisons were performed using Fisher's exact test through R version 3.0.2. Four types of caregivers were considered: mothers (regardless of their match sharing care), grandmothers, nannies, and daycare providers. Significant differences were found among the caregivers in regard to the ordination of three of the childcare systems: face-to-face, basic care, and body stimulation.

Significant association was found in regard to the type of caregiver and valorization of the face-to-face system. Mothers in general value this system the most $\left(x^{2}{ }_{3}=13.60\right.$; $p<.05)$. This finding is consistent with the results obtained in the study conducted by Seidl-de-Moura et al. (2008), in which a tendency of more frequent face-to-face interactions was observed in the mother and one-month old infant pairs in the city of Rio de Janeiro, Brazil. One should, however, consider the discussion presented in the study by Martins et al. (2009), who compares two distinct Brazilian contexts. The study involves mothers from the capital not

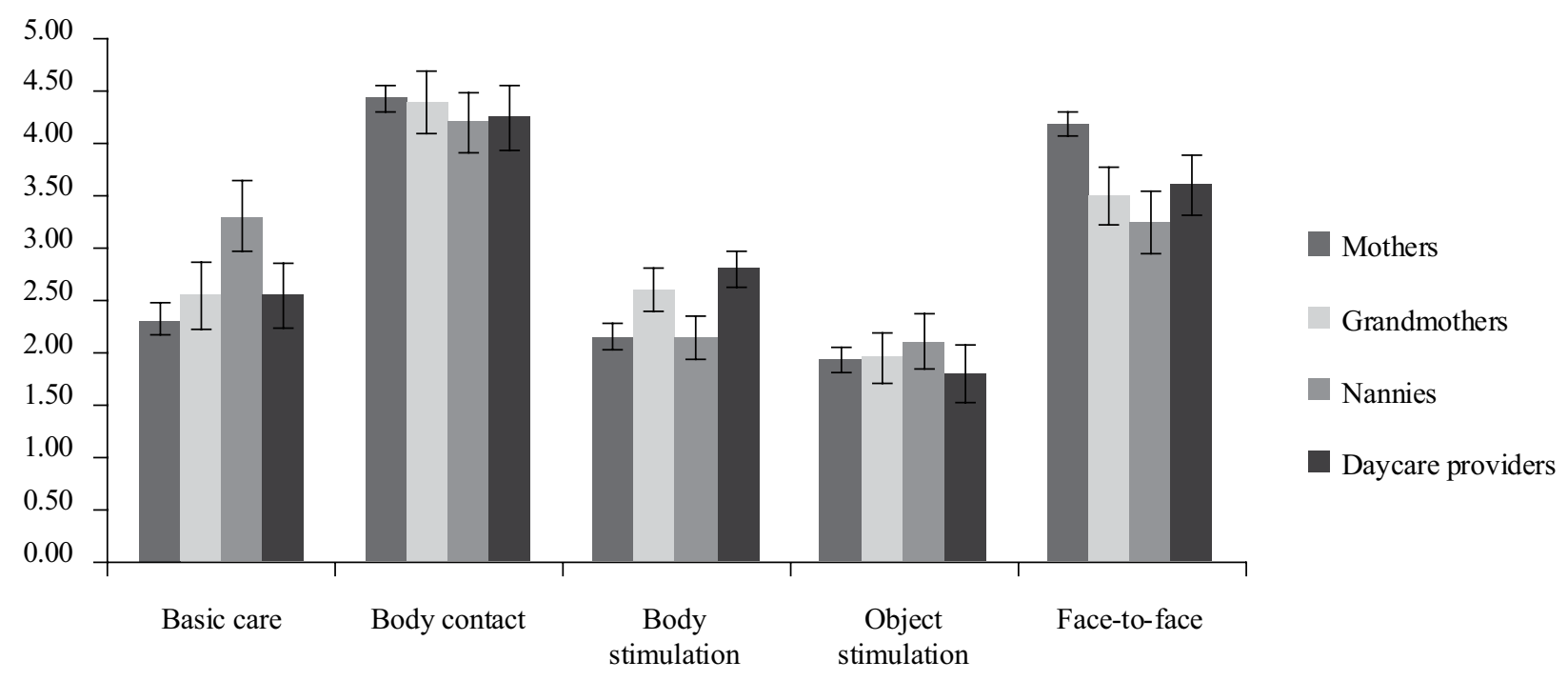

Figure 1. Valorization of systems by the different types of caregivers.

valuing childcare more than mothers living in the interior of the state. Differences regarding body contact were not found between the groups. Therefore, according to the theoretical model proposed by Keller (2013), the groups were equivalent in terms of interpersonal or interdependency relationships. In summary, all the caregivers valued childcare systems that involve both autonomy and relationship, but the mothers were those who valued a system the most for the development of autonomy among their children.
The other differences found indicate that the nannies tend to attribute more importance than mothers to basic care $\left(x_{3}^{2}=8.13 ; p<.05\right)$, while the daycare providers gave priority to body stimulation, with statistical significance when compared to mothers and nannies $\left(x_{3}^{2}=10.85 ; p<\right.$ $.05)$. The valorization of basic care on the part of nannies may be explained by the fact that this is the type of care they are expected to provide to the child under their care, i.e., to meet the child's basic needs such as food and hygiene. Another finding to be discussed is the valorization of body 
stimulation by educators in contrast to object stimulation. This contrasts with the observed among pairs of mothers and five-month old infants (Seidl-de-Moura et al., 2008), in which interactions promoted by the mothers and mediated by objects predominated. One possibility is that providers valued what is expected from them and see body stimulation as an important complement to basic care. Additionally, we have to take into account that interactions usually focused on object stimulation demand longer periods of time exclusively dedicated to the baby, in comparison to basic care and providers are usually responsible for simultaneously providing care to a group of children.

No significant differences were observed among the grandmothers in regard to the priority they give to childcare systems. Based on this result, one of the hypothesis of this study concerning this group was not confirmed, which conflicts with the results reported by Ruela (2006), that grandmothers would tend to value interdependence more, which according to the model adopted, would be more strongly linked to body contact. One potential explanation is that the mothers and grandmothers studied by Ruela lived in rural areas. In the urban context, the generational differences may be minimized, influenced by the transformations that take place due to urbanization and education, as Martins et al. (2009) seem to indicate.

To test this hypothesis and considering not only evidence found in the literature concerning the importance of education in influencing how much autonomy and interdependence is valued, but also the fact that the participants (mothers, grandmothers, nannies, and daycare providers) had diverse levels of education, we compared the importance assigned to each system according to level of education. A significant effect was found in regard to schooling on the valorization of the face-to-face exchange system. Caregivers (mothers, grandmothers, nannies, and daycare providers) with higher levels of education tended to attribute greater importance to this system $\left(x_{8}^{2}=15.77 ; p<.05\right)$. This result is in line with previous Brazilian evidence regarding the role of schooling in the valorization of autonomy (Seidl-de-Moura et al., 2013). This system, characteristic of a path of development of an autonomous self, is more prevalent in educated urban contexts. The inverse effect was observed in regard to the importance given to basic care. Women with lower levels of education tended to assign the highest importance to this system $\left(x_{8}^{2}=20.38 ; p<.05\right)$, which reinforces the idea of a primary system that does not depend on much elaboration, arising from the species' legacy of keeping offspring alive (Keller, 2013). No significant result was found in this type of analysis for the other systems. These results are consistent with the study by Greenfield et al. (2008).

Another aspect to highlight is the time of ontogenesis within the first year of life, in which one considers the childcare systems and their importance for those who care for babies. Mothers of children at different stages of the first year of their children's lives participated in this study: a little more than $30 \%$ had children from two to six months old and almost $70 \%$ had from seven-month to one-year old children. This is very important information because object stimulation, which is more frequently observed among children from five to six months of age (Seidl-de-Moura et al., 2008), was perhaps more highly valued. It is possible the body contact and face-to-face systems, more frequent in the first months of development, were more frequently valued by the caregivers because the value assigned to the care systems and beliefs in this regard are not directly related to the child's age. Kruskal-Wallis analyses were used to test the hypothesis that the baby's age influenced the importance assigned to each system, but no significant results were found.

\section{Final Considerations}

This study sought to contribute to our understanding of the dynamics of paths of development of self when different actors are involved in the routine of childcare. We used the care systems and assessed the importance these individuals assigned to the models to identify indicators of these paths. When valuing aspects of interaction, such as face-to-face and object stimulation, the caregiver shows a predominantly distal parenting style, enabling an experience of autonomy and separation. On the other hand, when the caregiver values body contact and stimulation, she shows a predominantly proximal parenting style, valuing interpersonal relationships the most (Martins et al., 2010).

One of the hypotheses that related to the mothers was confirmed and the set of evidence was expanded, pointing to a tendency to value related autonomy in the development of Brazilian children, now not only by mothers, but also by other caregivers, as well. It is indicated by the valorization of childcare systems that give priority to autonomy (face-to-face) and interdependence (body contact). The understanding of autonomy/relationship dynamics was broadened, confirming the role of education and indicating that autonomy is relatively more valued by mothers in comparison to other caregivers. These results differ from those reported by Friedlmeier et al. (2008) concerning Brazilian providers, who presented a greater tendency to value interdependence in comparison to caregivers of two countries, including Brazilian mothers.

This study has limitations and needs to be deepened and broadened to better understand the characteristics of the cultural context in which Brazilian children develop. One of its limitations is the relatively small number of participants. Larger samples enable greater security in testing hypotheses. Additionally, it was composed of mothers living in Rio de Janeiro only. In this sense, this study is exploratory and should be replicated in other contexts, other states, and non-urban environments with larger samples. Only one instrument was used, a semi-structured interview in which a set of stimuli was presented for the caregivers to provide responses. This was an option that enabled differentiated answers and was suitable to analysis according to the theoretical framework 
used. However, other valid and consistent methodological tools, which would enable additional and perhaps more sophisticated analysis, should be used in future studies. Observational studies are particularly important and necessary, together with those including the application of scales developed to assess the valorization of autonomy and interdependence in Brazilian contexts. Despite these limitations, this investigation contributes to the literature concerning childcare provided by different actors, which is still incipient. It is also an advancement of the state of knowledge in the field of development in Brazilian contexts and for the development of proposals for interventions and health promotion programs directed to diverse caregivers.

\section{References}

Bahia, C. C. S. (2008). O pensar e o fazer na creche: Um estudo a partir de crenças de mães e professoras (Unpublished doctoral dissertation). Universidade Federal do Pará, Belém, PA.

Brooks-Gunn, J., Han, W. J., \& Waldfogel, J. (2002). Maternal employment and child cognitive outcomes in the first three years of life: The NICHD study of early child care. Child Development, 73(4), 1052-1072. doi:10.1111/1467-8624.00457

Chen, J. H. (2013). Multiple childcare arrangements and health outcomes in early childhood. Maternal and Child Health Journal, 17(3), 448-455. doi:10.1007/s10995-012-1016-9

Fanti, C. M. (2006). Padrões mediacionais na relação babácriança em ambiente doméstico (Unpublished master's thesis). Universidade Federal da Bahia, Salvador, BA.

Field, A. P. (2009). Discovering statistics using IBM SPSS statistics. London, England: SAGE.

Friedlmeier, W., Schäfermeier, E., Vasconcellos, V., \& Trommsdorff, G. (2008). Self-construal and cultural orientation as predictors for developmental goals: A comparison between Brazilian and German caregivers. The European Journal of Developmental Psychology, 5(1), 39-67. doi:10.1080/17405620600751085

Greenfield, P. M., Flores, A., Davis, H., \& Salimkhan, G. (2008). What happens when parents and nannies come from different cultures? Comparing the caregiving belief systems of nannies and their employers. Journal of Applied Developmental Psychology, 29(4), 326-336. doi:10.1016/j.appdev.2008.04.002

Hansen, K., \& Hawkes, D. (2009). Early childcare and child development. Journal of Social Policy, 38(2), 211-239. doi:10.1017/S004727940800281X

Instituto Brasileiro de Geografia e Estatística (2010). Pesquisa Nacional por Amostra de Domicílios. Retrieved from http://www.sidra.ibge.gov.br/bda/tabela/listabl. $\operatorname{asp} ? \mathrm{z}=$ pnad \&o $=3 \& \mathrm{i}=\mathrm{P} \& \mathrm{c}=2863$

Keller, H. (2012). Autonomy and relatedness revisited: Cultural manifestations of universal human needs. Child Development Perspectives, 6(1), 12-18. doi:10.1111/j.1750-8606.2011.00208.x
Keller, H. (2013). Cultures of infancy. Mahwah, NJ: Lawrence Erlbaum.

Keller, H., \& Otto, H. (2009). The cultural socialization of emotion regulation during infancy. Journal of Cross-Cultural Psychology, 40(6), 996-1011. doi:10.1177/0022022109348576

Lordelo, E. R., Carvalho, A. M. A., \& Koller, S. H. (Orgs.). (2002). Infância brasileira e contextos de desenvolvimento. São Paulo, SP: Casa do Psicólogo.

Martins, G. D. F., Macarini, S. M., Vieira, M. L., Sachetti, V. A. R., Seidl-de-Moura, M. L., \& Bussab, V. S. R. (2009). Cuidado parental e apoio social em mães residentes na capital e interior de Santa Catarina. Interação em Psicologia, 13(1), 25-35.

Martins, G. D. F., Macarini, S. M., Vieira, M. L., Seidl-de-Moura, M. L., Bussab, V. S. R., \& Cruz, R. M. (2010). Construção e validação da Escala de Crenças Parentais e Práticas de Cuidado (E-CPPC) na primeira infância. Psico-USF, 15(1), 23-34. doi:10.1590/S1413-82712010000100004

Mendes, D. M. L. F., \& Seidl-de-Moura, M. L. (2013). O envelope narrativo e o desenvolvimento do self: Um estudo longitudinal com mães e bebês nos seis primeiros meses de vida. Interação em Psicologia, 17(1), 37-46.

Pluess, M., \& Belsky, J. (2009). Differential susceptibility to rearing experience: The case of childcare. Journal of Child Psychology and Psychiatry, 50(4), 396-404. doi:10.1111/j.1469-7610.2008.01992.x

Rapoport, A., \& Piccinini, C. A. (2004). A escolha do cuidado alternativo para o bebê e a criança pequena. Estudos de Psicologia (Natal), 9(3), 497-503. doi:10.1590/S1413-294X2004000300012

Ruela, S. F. (2006). Um estudo intergeracional de crenças valorizadas por mães em uma comunidade rural do estado do Rio de Janeiro (Unpublished master's thesis). Universidade do Estado do Rio de Janeiro, Rio de Janeiro, Brasil.

Seidl-de-Moura, M. L., Carvalho, R. V. C., \& Vieira, M. L. (2013). Brazilian mothers' cultural models: Socialization for autonomy and relatedness. In M. L. Seidl-de-Moura (Ed.). Parenting in South American and African contexts. Retrieved from http://www.intechopen.com/books/parenting-in-southamerican-and-african-contexts/brazilian-mothers-culturalmodels-socialization-for-autonomy-and-relatedness\#SEC1

Seidl-de-Moura, M. L., Ribas, A. F. P., Seabra, K. C., Pessôa, L. F., Nogueira, S. E., Mendes, D. M. L. F., ... Vicente, C. C. (2008). Interações mãe-bebê de um e cinco meses: Aspectos afetivos, complexidade e sistemas parentais predominantes. Psicologia: Reflexão e Crítica, 21(1), 66-73. doi:10.1590/S0102-79722008000100009

Super, C. M., \& Harkness, S. (2014). Culture and infancy. In J. G. Bremner \& T. D. Wachs (Eds.). The Wiley-Blackwell handbook of infant development (2nd ed., pp. 623-649). Oxford, England: Wiley-Blackwell. 
Tanskanen, A. O. (2013). The association between grandmaternal investment and early years overweight in the UK. Evolutionary Psychology, 11(2), 417-425.

Vieira, M. L., Seidl-de-Moura, M. L., Macarini, S. M., Martins, G. D. F., Lordelo, E. R., Tokumaru, R. S., \& Oliva, A. D. (2010). Autonomy and interdependence: Beliefs of Brazilian mothers from state capitals and small towns. The Spanish Journal of Psychology, 13(2), 818-826. doi:10.1017/S113874160000247X

Maria Lucia Seidl-de-Moura is a Full Professor of the Instituto de Psicologia at the Universidade do Estado do Rio de Janeiro. Luciana Fontes Pessôa is an Assistant Professor at the Pontifícia Universidade Católica do Rio de Janeiro.

Dandara de Oliveira Ramos is a Ph.D. candidate of the Graduate Program in Collective Health at the Universidade do Estado do Rio de Janeiro.

Deise Maria Leal Fernandes Mendes is a Professor at the Universidade do Estado do Rio de Janeiro.

Ana Carolina Monnerat Fioravanti-Bastos is a Professor at the Universidade Federal Fluminense.

Luciana Brooking Teresa Dias is a Ph.D. candidate at the Graduate Program in Social Psychology of the Universidade do Estado do Rio de Janeiro.

Received: Apr. 8, 2014

1st Revision: Aug. 5, 2014

Approved: Aug. 8, 2014

How to cite this article:

Seidl-de-Moura, M. L., Pessôa, L. F., Ramos, D. O., Mendes, D. M. L. F., Fioravanti-Bastos, A. C. M., \& Dias, L. B. T. (2014). Beliefs about the care of babies of mothers, nannies, grandmothers and day-care center educators. Paidéia (Ribeirão Preto), 24(59), 341-349. doi: 10.1590/1982-43272459201408 


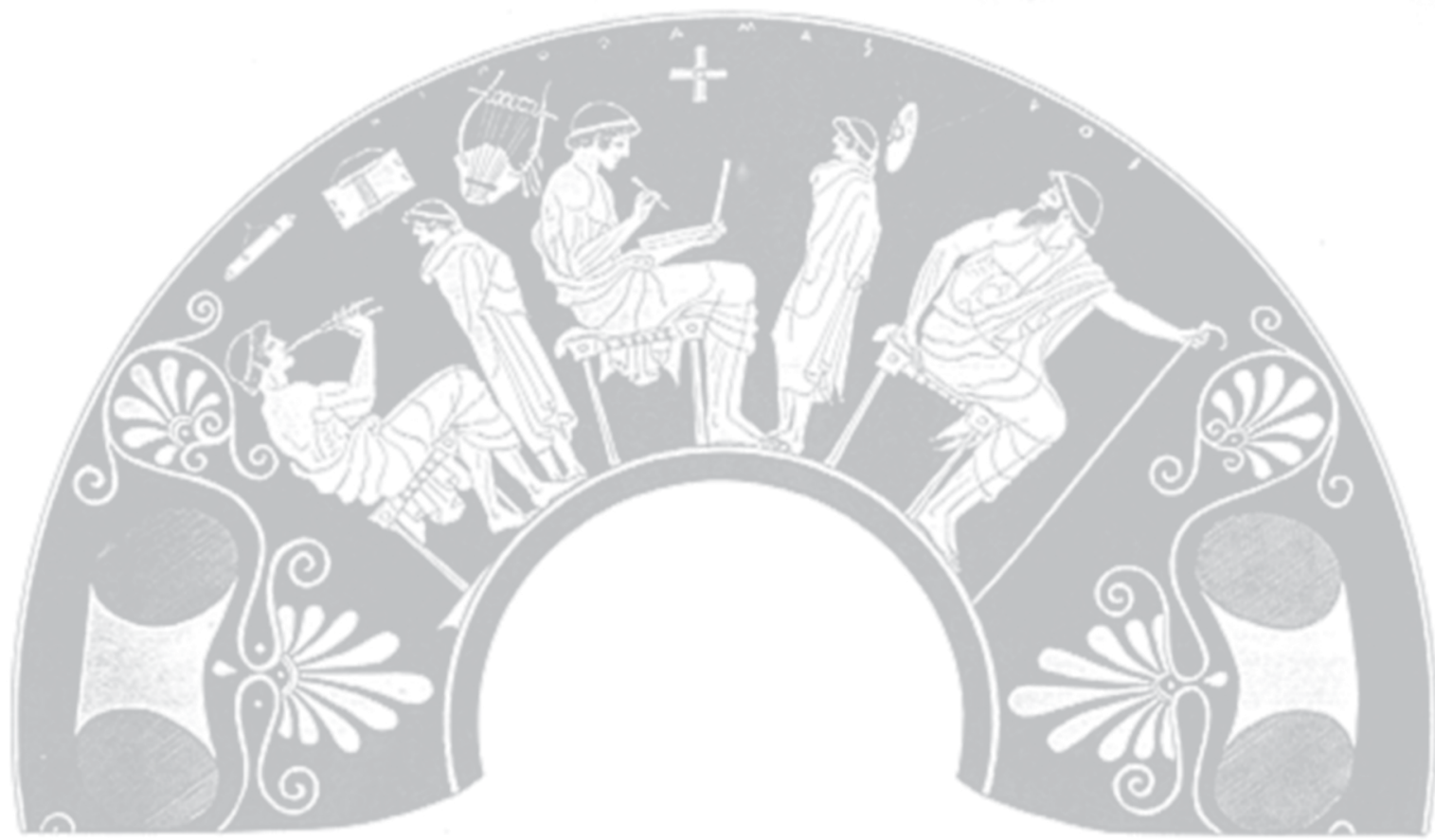

